\title{
Prediksi Neraca Air DAS Tirtomoyo Dengan Metode GR2M Berdasar- kan Hujan Debit 15 Harian Tahun 2018
}

\author{
Ridwan Kresna Bayu ${ }^{1)}$, Rintis Hadiani ${ }^{2}$, Solichin ${ }^{3)}$ \\ 1) Mahasiswa Fakultas Teknik, Prodi Teknik Sipil, Universitas Sebelas Maret \\ 2) Pengajar Fakultas Teknik, Prodi Teknik Sipil, Universitas Sebelas Maret \\ 3) Pengajar Fakultas Teknik, Prodi Teknik Sipil, Universitas Sebelas Maret \\ J1. Ir. Sutami 36A, Surakarta 57126; Telp. 0271-634524. Email: ridwanbayu28@gmail.com
}

\begin{abstract}
Water management is needed to maintain water availability in a watershed. Water requirment in a watershed are met if availability water is provided. It is necessary to know the water balance that occurs so that water management can be carried out optimally.

This research was carried out in the Tirtomoyo watershed. This study analyzes the mainstay discharge with GR2M method. GR2M method is still rarely used to calculate water discharge in Indonesia, although only using two parameters, namely soil moisture capacity and coefficient of soil infiltration.

The results show that water availability in Tirtomoyo watershed can not fulfill the water needs in 2018. The biggest deficit occurred in the second 15 daily period of April namely $-8,2848 \mathrm{~m}^{3} /$ second and the biggest surplus occurred in the second 15 daily period of February namely $8,1220 \mathrm{~m}^{3} /$ second.
\end{abstract}

Keywords: water balance, GR2M, Tirtomoyo watershed

\begin{abstract}
Abstrak
Pengelolan air diperlukan untuk menjaga ketersediaan air di suatu DAS (Daerah Aliran Sungai). Kebutuhan air di suatu DAS terpenuhi apabila ketersediaan air tercukupi. Perlu diketahui neraca air yang terjadi agar pengelolaan air dapat dilakukan secara optimal.

Penelitian ini dilakukan di DAS Tirtomoyo. Penelitian ini menganalisis debit andalan dengan metode GR2M. Metode GR2M jarang digunakan untuk menghitung debit di Indonesia, walaupun hanya menggunakan dua parameter, yaitu kapasitas simpanan kelembaban tanah dan koefisien penyerapan tanah.

Hasil menunjukkan bahwa ketersediaan air di DAS Tirtomoyo tidak dapat memenuhi seluruh kebutuhan air di tahun 2018. Defisit air terbesar terjadi pada bulan April periode 15 harian ke dua sebesar $-8,2848 \mathrm{~m}^{3} /$ detik sedangkan surplus air terbesar terjadi pada bulan Februari periode 15 harian ke dua sebesar 8,1220 m³/detik.
\end{abstract}

Kata Kunci: neraca air, GR2M, DAS Tirtomoyo

\section{PENDAHULUAN}

Air menjadi hal penting di dunia terutama di negara Indonesia, dahulu ketersediaan air dirasa melimpah. Namun sekarang ketersediaan air mengalami pergeseran karena adanya berbagai faktor sehingga ketersediaan air berkurang (Kajian Spasial Kesetimbangan Air pada Skala DAS, 2008).

Salah satu sumber air yang diperoleh masyarakat berasal dari sungai. DAS (Daerah Aliran Sungai) adalah suatu kesatuan wilayah tata air yang terbentuk secara alami. Dimana air meresap atau mengalir melalui sungai dan anakanak sungai yang bersangkutan. Guna dari DAS adalah menerima, menyimpan dan mengalirkan air yang ada melalui sungai (SNI 1724-2015). Salah satu DAS yang ada di Indonesia adalah DAS Tirtomoyo yang menjadi wilayah penelitian ini.

Pengelolan air diperlukan untuk menjaga ketersediaan air di suatu DAS. Kebutuhan air di suatu DAS terpenuhi apabila ketersediaan air mencukupi. Besarnya jumlah debit air yang mengalir pada sungai dipengaruhi oleh curah hujan.

Dalam penelitian ini debit air dihitung dengan metode GR2M, metode ini masih jarang digunakan di Indonesia. Metode GR2M memiliki kelebihan dibanding metode lain, yaitu tidak mempertimbangkan DAS basah maupun kering. Metode ini menggunakan sedikit data, yaitu curah hujan dan evapotranspirasi serta dua parameter model (Yosephina Puspa Setyoasri, 2015). Metode GR2M lebih sederhana dibandingkan metode Mock yang menggunakan banyak parameter yaitu kapasitas kelembaban tanah, keseimbangan air permukaan, kandungan air tanah, pentimpanan air tanah, koefisien infiltrasi, dan tampungan awal penyimpanan air tanah sehingga bila ada salah satu parameter atau data tidak tersedia maka metode Mock tidak dapat digunakan. 


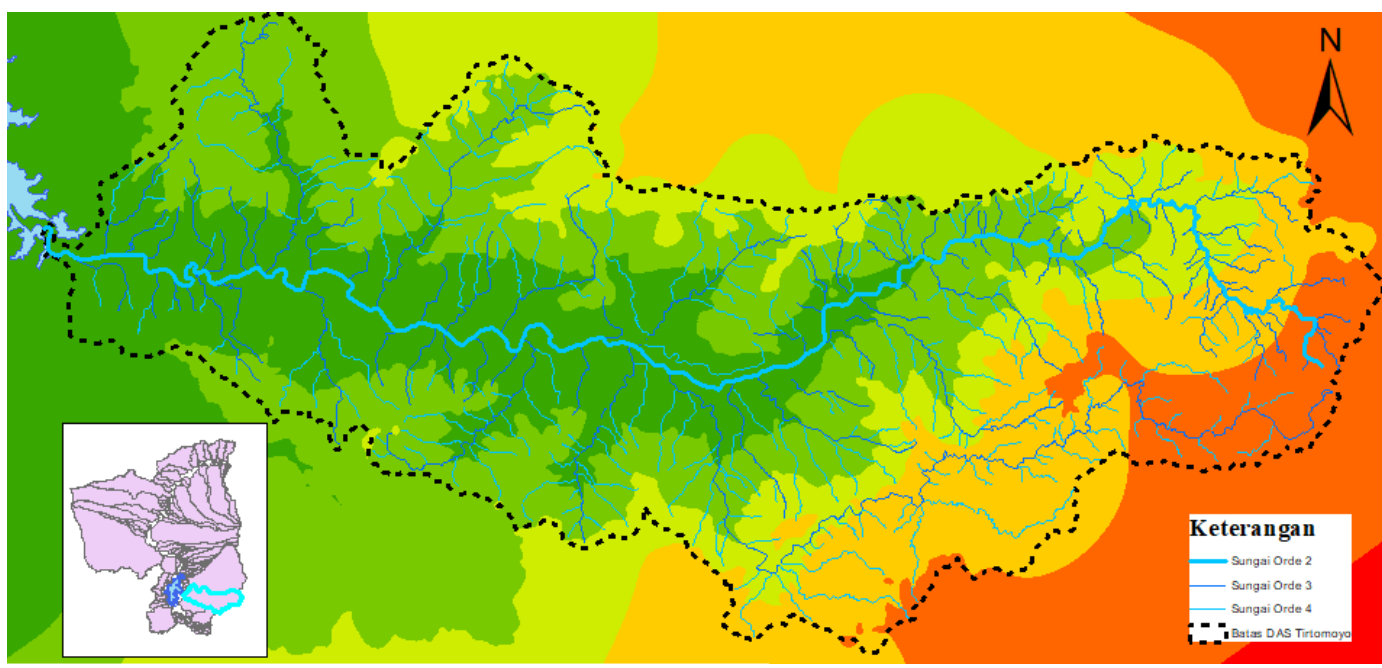

Gambar 1. Daerah aliran sungai Tirtomoyo

Gambar 1 merupakan daerah aliran sungai Tirtomoyo yang menjadi wilayah penelitian.

\section{LANDASAN TEORI}

\section{Dasar Teori}

Air menjadi hal penting di dunia terutama di negara Indonesia, dahulu ketersediaan air dirasa melimpah. Namun sekarang ketersediaan air mengalami pergeseran karena adanya berbagai faktor sehingga ketersediaan air berkurang (Kajian Spasial Kesetimbangan Air pada Skala DAS, 2008).

Neraca air adalah gambaran mengenai ketersediaan air dan pemanfaatannya di suatu wilayah dalam kurun waktu tertentu, untuk pencegahan kekeringan dapat dilakukan dengan menganalisa neraca air yang terjadi di wilayah tersebut (Cahyo Adi Wibowo, 2012).

Debit air yang mengalir di suatu sungai sangat dipengaruhi oleh curah hujan yang terjadi di DAS tersebut. Ketersediaan air di musim hujan dan musim kemarau berbeda, sehingga kebutuhan air tidak terpenuhi, oleh sebab itu perlu adanya pengaturan pemanfaatan air di wilayah tersebut (Lukman Hakim Nugroho Saksono, 2013).

Siklus hidrologi di suatu wilayah sangat dipengaruhi oleh curah hujan yang terjadi di wilayah tersebut. Selain curah hujan, evapotranspirasi yang terjadi juga berpengaruh terhadap siklus hidrologi (Alfrida Irfani, 2012).

Metode GR2M memiliki kelebihan dibanding metode lain, yaitu tidak mempertimbangkan DAS basah maupun kering. Metode ini menggunakan sedikit data, yaitu curah hujan dan evapotranspirasi serta dua parameter model (Yosephina Puspa Setyoasri, 2015).

\section{METODE PENELITIAN}

Penelitian ini menggunakan data sekunder. Data sekunder meliputi data hujan harian stasiun Hujan Balong, Puter dan Watugede, data statistik, data luas sawah, pola tanam, dan peta DAS Tirtomoyo.

\section{HASIL DAN PEMBAHASAN}

\section{Uji Kepanggahan}

Uji kepanggahan data hujan menggunakan uji kurva massa ganda. Data hujan tahun 2008-2017 diperoleh dari BBWS. Uji kepanggahan metode kurva massa ganda berdasarkan perbandingan jumlah hujan komulatif stasiun hujan yang ditinjau dengan rerata hujan tahunan komulatif dua atau lebih stasiun hujan yang berada di sekitarnya. Data Jumlah curah hujan stasiun Balong tahun 2008 dapat dilihat pada Lampiran. Hasil uji kepanggahan stasiun hujan Balong, Puter dan Watugede dapat dilihat pada Gambar 2. 


\section{Uji Validitas Data Hujan}

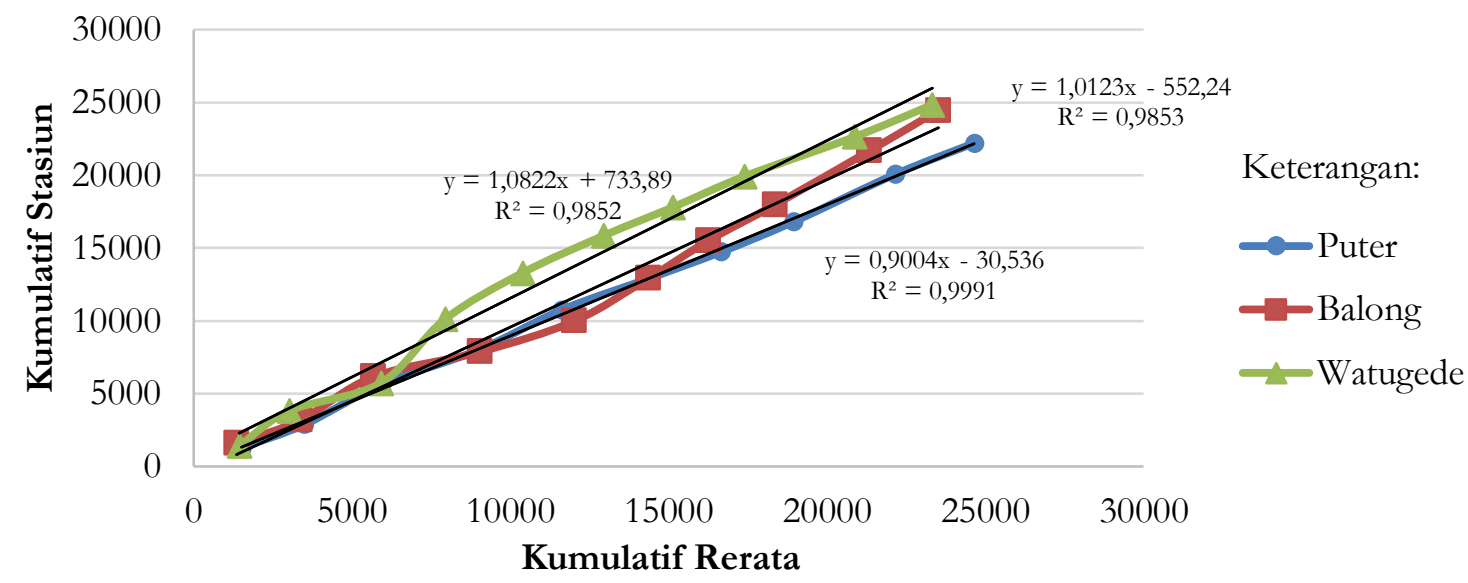

Gambar 2. Kurva Massa Ganda

Dari Gambar 2 diketahui nilai R2 dari masing-masing stasiun hujan mendekati satu sehingga dapat disimpulkan bahwa data hujan yang digunakan panggah.

\section{Hujan Wilayah}

Hujan wilayah mewakili hujan yang terjadi di seluruh DAS Tirtomoyo. Koefisien Thiessen digunakan sebagai pengali dalam perhitungan hujan wilayah. Rekapitulasi hujan wilayah dapat dilihat pada Tabe1 1.

Tabel 1 Rekapitulasi hujan wilayah

\begin{tabular}{rrrrrrrrrrrrrr}
\hline \multirow{2}{*}{ Tahun } & \multicolumn{2}{c}{ Jan } & \multicolumn{2}{c}{ Feb } & \multicolumn{2}{c}{ Mar } & \multicolumn{2}{c}{ Apr } & \multicolumn{2}{c}{ Mei } & \multicolumn{2}{c}{ Jun } \\
\cline { 2 - 16 } & I & II & \multicolumn{1}{c}{ I } & \multicolumn{1}{c}{ II } & \multicolumn{1}{c}{ I } & \multicolumn{1}{c}{ II } & I & II & I & II & \multicolumn{1}{l}{ I } & \multicolumn{1}{c}{ II } \\
\hline 2008 & 132 & 150 & 243 & 167 & 205 & 140 & 130 & 41 & 5,3 & 0 & 0 & 0 \\
\hline 2009 & 122 & 182 & 273 & 203 & 47 & 137 & 92 & 82 & 52 & 159 & 72 & 0 \\
\hline 2010 & 75 & 66 & 204 & 151 & 279 & 335 & 65 & 69 & 154 & 69 & 82 & 21 \\
\hline 2011 & 179 & 148 & 69 & 54 & 163 & 286 & 145 & 160 & 198 & 92 & 21 & 2,6 \\
\hline 2012 & 290 & 153 & 110 & 300 & 359 & 207 & 175 & 63 & 131 & 4,3 & 2,4 & 24 \\
\hline 2013 & 277 & 183 & 213 & 213 & 91 & 58 & 163 & 135 & 25 & 127 & 128 & 122 \\
\hline 2014 & 254 & 222 & 116 & 124 & 59 & 125 & 138 & 51 & 15 & 56 & 0 & 114 \\
\hline 2015 & 195 & 239 & 311 & 123 & 280 & 119 & 198 & 238 & 70 & 25 & 11 & 0 \\
\hline 2016 & 117 & 209 & 216 & 193 & 198 & 117 & 205 & 92 & 69 & 86 & 76 & 66 \\
\hline 2017 & 182 & 230 & 267 & 128 & 127 & 92 & 226 & 219 & 36 & 33 & 59 & 24 \\
\hline
\end{tabular}

\section{Lanjutan Tabel 1}

\begin{tabular}{|c|c|c|c|c|c|c|c|c|c|c|c|c|}
\hline \multirow{2}{*}{ Tahun } & \multicolumn{2}{|c|}{ Jul } & \multicolumn{2}{|c|}{ Ags } & \multicolumn{2}{|c|}{ Sep } & \multicolumn{2}{|c|}{ Okt } & \multicolumn{2}{|c|}{ Nov } & \multicolumn{2}{|c|}{ Des } \\
\hline & I & II & $\mathrm{I}$ & II & $\mathrm{I}$ & II & $\mathrm{I}$ & II & $\mathrm{I}$ & II & $\mathrm{I}$ & II \\
\hline 2008 & 0 & 0 & 0 & 0 & 0 & 0 & 0 & 0 & 0 & 0 & 120 & 93 \\
\hline 2009 & 0 & 0 & 0 & 0 & 0 & 0 & 0 & 0 & 55 & 131 & 40 & 82 \\
\hline 2010 & 20 & 16 & 4 & 23 & 133 & 132 & 41 & 404 & 0 & 0 & 221 & 145 \\
\hline 2011 & 0 & 0,6 & 0 & 0,6 & 0 & 0 & 0,6 & 63 & 185 & 182 & 137 & 338 \\
\hline 2012 & 0 & 0 & 0 & 0 & 0 & 0 & 5,4 & 30 & 51 & 233 & 210 & 234 \\
\hline 2013 & 60 & 11 & 0 & 0 & 0 & 0 & 0 & 93 & 124 & 63 & 110 & 334 \\
\hline 2014 & 24 & 4,5 & 0 & 0 & 0 & 0 & 0 & 0 & 78 & 215 & 181 & 360 \\
\hline 2015 & 0 & 0 & 0 & 0 & 0 & 0 & 0 & 0 & 65 & 105 & 154 & 96 \\
\hline 2016 & 52 & 115 & 39 & 37 & 37 & 261 & 304 & 97 & 237 & 214 & 193 & 119 \\
\hline 2017 & 3,5 & 21 & 0 & 0 & 0 & 111 & 49 & 16 & 59 & 518 & 0 & 0 \\
\hline
\end{tabular}


Tabel 1 adalah rekapitulasi hujan wilayah 15 harian pada DAS Tirtomoyo selama 10 tahun terakhir.

\section{Prediksi Hujan}

Pada penelitian ini data hujan pada tahun 2018 belum diperoleh, untuk mendapatkan data hujan tahun 2018 perlu

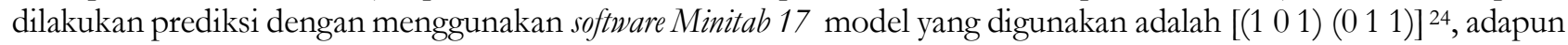
data yang digunakan untuk memprediksi hujan di tahun 2018 adalah data hujan wilayah tahun 2008-2017.

\section{Evapotranpirasi}

Pada penelitian ini nilai evapotranspirasi diperoleh dengan metode Penman-Monteith yang dihitung menggunakan software CROPWAT 8.0. Data klimatologi diperoleh dari stasiun klimatologi Ngancar, adapun data input yang diperlukan untuk mencari nilai evapotranspirasi sebagai berikut:

- Koordinat stasiun klimatologi,

- Ketinggian stasiun klimatologi,

- Kelembaban udara,

- Kecepatan angin,

- Suhu udara, dan

- Penyinaran matahari.

\section{Debit Lapangan}

Debit lapangan yang diperoleh dari Pos Pengamatan Sungai Sulingi perlu diubah untuk mendapatkan nilai debit lapangan DAS Tirtomoyo dengan membandingkan luas daerahnya.

\section{Perhitungan Simulasi Debit GR2M}

Dalam menghitung simulasi hujan-debit dengan metode GR2M ada beberapa data yang diperlukan. Data tersebut adalah:

- Data hujan tahun $2008-2017$

- Prediksi hujan tahun 2018

- Data evapotranspirasi tahun 2008 - 2017

- Kapasitas produksi $\left(\mathrm{x}_{1}\right)$ diperoleh dengan solver $=640$

$-\mathrm{x}_{2}$ diperoleh dengan solver $=1,02$

- Nilai routing awal $=\mathrm{R}=30 \mathrm{~mm}($ maksimum $=60 \mathrm{~mm})$

Hasil perhitungan dengan debit simulasi GR2M 15-harian dikorelasikan dengan debit lapangan. Perhitungan korelasi menggunakan fasilitas Ms. Excel. Nilai korelasi pada tahun $2008=0,8524$, karena nilai korelasi tersebut lebih dari 0,8 maka dapat dinyatakan bahwa debit simulasi GR2M 15-harian layak digunakan di DAS Tirtomoyo.

\section{Debit Andalan}

Debit andalan atau Q80 didapatkan dengan mengurutkan data debit yang diperoleh dari urutan terbesar ke terkecil kemudian dipilih data yang dapat dilampaui sebanyak $80 \%$.

Tabel 2 Rekapitulasi debit bulanan dan ranking yang dipilih untuk Q80

\begin{tabular}{|c|c|c|c|c|c|c|c|c|c|c|c|c|c|}
\hline \multirow{2}{*}{ Rank } & \multirow{2}{*}{ Probabilitas } & \multicolumn{12}{|c|}{ Debit (mm/bulan) } \\
\hline & & Jan & Feb & Mar & Apr & Mei & Jun & Jul & $\mathrm{Ags}$ & Sep & Okt & Nov & Des \\
\hline 1 & 0,08 & 415 & 399 & 509 & 361 & 266 & 188 & 95 & 59 & 128 & 313 & 339 & 368 \\
\hline 2 & 0,17 & 411 & 361 & 499 & 310 & 184 & 111 & 90 & 49 & 115 & 305 & 267 & 357 \\
\hline 3 & 0,25 & 388 & 343 & 352 & 280 & 159 & 107 & 74 & 32 & 59 & 93 & 208 & 280 \\
\hline 4 & 0,33 & 385 & 339 & 318 & 279 & 151 & 100 & 49 & 28 & 16 & 21 & 140 & 273 \\
\hline 5 & 0,42 & 306 & 331 & 308 & 234 & 135 & 92 & 48 & 21 & 15 & 21 & 77 & 270 \\
\hline 6 & 0,50 & 265 & 327 & 285 & 223 & 134 & 70 & 32 & 17 & 11 & 10 & 75 & 262 \\
\hline 7 & 0,58 & 258 & 317 & 253 & 195 & 122 & 67 & 28 & 15 & 10 & 7 & 60 & 234 \\
\hline 8 & 0,67 & 186 & 301 & 174 & 161 & 111 & 61 & 26 & 13 & 9 & 6 & 56 & 99 \\
\hline 9 & 0,75 & 154 & 224 & 166 & 161 & 93 & 47 & 23 & 13 & 8 & 6 & 26 & 68 \\
\hline
\end{tabular}




\begin{tabular}{cccccccccccccc}
10 & 0,83 & 109 & 222 & 154 & 159 & 69 & 41 & 22 & 12 & 7 & 5 & 18 & 50 \\
\hline 11 & 0,92 & 74 & 127 & 132 & 146 & 43 & 20 & 11 & 7 & 4 & 3 & 2 & 14 \\
\hline
\end{tabular}

Tabel 2 menunjukkan urutan ranking dan ranking yang dipilih adalah ranking 10 karena nilai probabilitasnya paling mendekati $80 \%$.

Tabel 3 Debit andalan

\begin{tabular}{|c|c|c|c|}
\hline \multirow{2}{*}{ Bulan } & \multirow{2}{*}{ Periode } & \multicolumn{2}{|c|}{ Q80 } \\
\hline & & (mm/15hari) & $\left(\mathrm{m}^{3} / \mathrm{dtk}\right)$ \\
\hline \multirow{2}{*}{ Jan } & 1 & 29,1404 & 4,5545 \\
\hline & 2 & 79,9093 & 12,4895 \\
\hline \multirow{2}{*}{ Feb } & 1 & 115,4361 & 18,0421 \\
\hline & 2 & 106,9420 & 16,7146 \\
\hline \multirow{2}{*}{ Mar } & 1 & 65,0989 & 10,1747 \\
\hline & 2 & 88,7030 & 13,8639 \\
\hline \multirow{2}{*}{ Apr } & 1 & 105,7801 & 16,5330 \\
\hline & 2 & 52,8771 & 8,2645 \\
\hline \multirow{2}{*}{ Mei } & 1 & 32,3878 & 5,0621 \\
\hline & 2 & 36,6009 & 5,7206 \\
\hline \multirow{2}{*}{ Jun } & 1 & 21,4506 & 3,3526 \\
\hline & 2 & 20,0391 & 3,1320 \\
\hline \multirow{2}{*}{ Jul } & 1 & 12,8540 & 2,0090 \\
\hline & 2 & 9,3969 & 1,4687 \\
\hline \multirow{2}{*}{ Ags } & 1 & 7,1203 & 1,1129 \\
\hline & 2 & 5,3721 & 0,8396 \\
\hline \multirow{2}{*}{ Sep } & 1 & 4,1121 & 0,6427 \\
\hline & 2 & 3,1932 & 0,4991 \\
\hline \multirow{2}{*}{ Okt } & 1 & 2,6547 & 0,4149 \\
\hline & 2 & 2,1175 & 0,3310 \\
\hline \multirow{2}{*}{ Nov } & 1 & 4,2768 & 0,6684 \\
\hline & 2 & 13,7985 & 2,1566 \\
\hline \multirow{2}{*}{ Des } & 1 & 19,6252 & 3,0673 \\
\hline & 2 & 30,4716 & 4,7626 \\
\hline
\end{tabular}

Tabel 3 adalah debit hujan 15 harian dari debit hujan bulanan yang dipilih berdasarkan Tabel 2.

\section{Kebutuhan Sumber Daya Air}

Data sekunder berupa jumlah penduduk dan jumlah ternak diperoleh dari BPS Kabupaten Wonogiri dan Pacitan, sedangkan data luas sawah diperoleh dari DPU Wonogiri dan BPS Kabupaten Pacitan. Kebutuhan air dihitung berdasarkan data yang telah diperoleh dengan persamaan-persamaan yang berlaku berdasarkan SNI 6728.1:2015 dan Dirjen Pengairan, Dep. PU, 1986. Hasil perhitungan dari data yang diperoleh dapat dilihat pada tabel 4, sebagai berikut: 
Tabel 4 Rekapitulasi kebutuhan air

\begin{tabular}{cccccccccc}
\hline \multirow{2}{*}{ Kebutuhan Air } & \multirow{2}{*}{ Satuan } & \multicolumn{2}{c}{ Jan } & \multicolumn{2}{c}{ Feb } & \multicolumn{2}{c}{ Mar } & \multicolumn{2}{c}{ Apr } \\
\cline { 3 - 10 } & & I & II & I & II & I & II & I & II \\
\hline RKI & $\mathrm{m}^{3} /$ detik & 0,19 & 0,19 & 0,19 & 0,19 & 0,19 & 0,19 & 0,19 & 0,19 \\
\hline Irigasi & $\mathrm{m}^{3} /$ detik & 0,14 & 0,13 & 0,13 & 0,00 & 0,00 & 0,00 & 3,89 & 5,71 \\
\hline Peternakan & $\mathrm{m}^{3} /$ detik & 0,01 & 0,01 & 0,01 & 0,01 & 0,01 & 0,01 & 0,01 & 0,01 \\
\hline Perikanan & $\mathrm{m}^{3} /$ detik & 0,00 & 0,00 & 0,00 & 0,00 & 0,00 & 0,00 & 0,00 & 0,00 \\
\hline $\begin{array}{c}\text { Pemeliharaan } \\
\text { Sungai }\end{array}$ & $\mathrm{m}^{3} /$ detik & 5,73 & 5,87 & 11,47 & 8,40 & 12,79 & 7,88 & 12,16 & 10,64 \\
\hline Jumlah & $\mathrm{m}^{3} /$ detik & 6,07 & 6,19 & 11,79 & 8,59 & 12,98 & 8,08 & 16,26 & 16,55 \\
\hline
\end{tabular}

Lanjutan Tabel 4

\begin{tabular}{cccccccccc}
\hline \multirow{2}{*}{ Kebutuhan Air } & \multirow{2}{*}{ Satuan } & \multicolumn{2}{c}{ Mei } & \multicolumn{2}{c}{ Jun } & \multicolumn{3}{c}{ Jul } & \multicolumn{2}{c}{ Ags } \\
\cline { 3 - 10 } & & I & II & I & II & I & II & I & II \\
\hline RKI & $\mathrm{m}^{3} /$ detik & 0,19 & 0,19 & 0,19 & 0,19 & 0,19 & 0,19 & 0,19 & 0,19 \\
\hline Irigasi & $\mathrm{m}^{3} /$ detik & 2,04 & 2,15 & 2,58 & 2,76 & 2,29 & 1,93 & 0,00 & 0,00 \\
\hline Peternakan & $\mathrm{m}^{3} /$ detik & 0,01 & 0,01 & 0,01 & 0,01 & 0,01 & 0,01 & 0,01 & 0,01 \\
\hline Perikanan & $\mathrm{m}^{3} /$ detik & 0,00 & 0,00 & 0,00 & 0,00 & 0,00 & 0,00 & 0,00 & 0,00 \\
\hline $\begin{array}{c}\text { Pemeliharaan } \\
\text { Sungai }\end{array}$ & $\mathrm{m}^{3} /$ detik & 4,21 & 2,57 & 1,78 & 1,30 & 0,98 & 0,75 & 0,59 & 0,46 \\
\hline Jumlah & $\mathrm{m}^{3} /$ detik & 6,44 & 4,93 & 4,55 & 4,25 & 3,47 & 2,88 & 0,79 & 0,66 \\
\hline
\end{tabular}

Lanjutan Tabel 4

\begin{tabular}{cccccccccc}
\hline \multirow{2}{*}{ Kebutuhan Air } & \multirow{2}{*}{ Satuan } & \multicolumn{2}{c}{ Sep } & \multicolumn{2}{c}{ Okt } & \multicolumn{2}{c}{ Nov } & \multicolumn{2}{c}{ Des } \\
\cline { 3 - 10 } & & I & II & I & II & I & II & I & II \\
\hline RKI & $\mathrm{m}^{3} /$ detik & 0,19 & 0,19 & 0,19 & 0,19 & 0,19 & 0,19 & 0,19 & 0,19 \\
\hline Irigasi & $\mathrm{m}^{3} /$ detik & 0,00 & 0,00 & 0,00 & 6,95 & 6,94 & 3,17 & 2,21 & 1,40 \\
\hline Peternakan & $\mathrm{m}^{3} /$ detik & 0,01 & 0,01 & 0,01 & 0,01 & 0,01 & 0,01 & 0,01 & 0,01 \\
\hline $\begin{array}{c}\text { Perikanan } \\
\mathrm{m}^{3} / \text { detik }\end{array}$ & 0,00 & 0,00 & 0,00 & 0,00 & 0,00 & 0,00 & 0,00 & 0,00 \\
\hline $\begin{array}{c}\text { Pemeliharaan } \\
\text { Sungai }\end{array}$ & $\mathrm{m}^{3} /$ detik & 0,37 & 0,29 & 0,24 & 0,19 & 0,16 & 0,13 & 0,54 & 1,60 \\
\hline Jumlah & $\mathrm{m}^{3} /$ detik & 0,56 & 0,49 & 0,44 & 7,34 & 7,30 & 3,50 & 2,95 & 3,20 \\
\hline
\end{tabular}

Tabel 4 menunjukkan nilai kebutuhan air yang terjadi tiap 15 hari pada DAS Tirtomoyo.

\section{Neraca Sumber Daya Air}

Neraca air ditentukan berdasarkan analisis keseimbangan ketersediaan air sungai dan kebutuhan air total di wilayah DAS Tirtomoyo. Saldo total pada tahun 2018 sebesar $-4,3933 \mathrm{~m}^{3} /$ detik atau $-0.1393 \times 10^{-6} \mathrm{~m}^{3} /$ tahun.

Tabel 5 Neraca air

\begin{tabular}{cccccccccc}
\hline \multirow{2}{*}{ Neraca Air } & \multirow{2}{*}{ Satuan } & \multicolumn{2}{c}{ Jan } & \multicolumn{2}{c}{ Feb } & \multicolumn{2}{c}{ Mar } & \multicolumn{2}{c}{ Apr } \\
\cline { 3 - 10 } & & I & II & I & II & I & II & I & II \\
\hline Ketersediaan & $\mathrm{m}^{3} /$ detik & 4,55 & 12,49 & 18,04 & 16,71 & 10,17 & 13,86 & 16,53 & 8,26 \\
\hline Kebutuhan & $\mathrm{m}^{3} /$ detik & 6,07 & 6,19 & 11,79 & 8,59 & 12,98 & 8,08 & 16,26 & 16,55 \\
\hline
\end{tabular}


Lanjutan Tabel 5

\begin{tabular}{cccccccccc}
\hline \multirow{2}{*}{ Neraca Air } & \multirow{2}{*}{ Satuan } & \multicolumn{2}{c}{ Mei } & \multicolumn{2}{c}{ Jun } & \multicolumn{3}{c}{ Jul } & \multicolumn{3}{c}{ Ags } \\
\cline { 3 - 10 } & & I & II & I & II & I & II & I & II \\
\hline Ketersediaan & $\mathrm{m}^{3} /$ detik & 5,06 & 5,72 & 3,35 & 3,13 & 2,01 & 1,47 & 1,11 & 0,84 \\
\hline Kebutuhan & $\mathrm{m}^{3} /$ detik & 6,44 & 4,93 & 4,55 & 4,25 & 3,47 & 2,88 & 0,79 & 0,66 \\
\hline Saldo & $\mathrm{m}^{3} /$ detik & $-1,38$ & 0,80 & $-1,20$ & $-1,12$ & $-1,46$ & $-1,41$ & 0,33 & 0,18 \\
\hline
\end{tabular}

Lanjutan Tabel 5

\begin{tabular}{cccccccccc}
\hline \multirow{2}{*}{ Neraca Air } & \multirow{2}{*}{ Satuan } & \multicolumn{2}{c}{ Sep } & \multicolumn{2}{c}{ Okt } & \multicolumn{2}{c}{ Nov } & \multicolumn{2}{c}{ Des } \\
\cline { 3 - 10 } & & I & II & I & II & I & II & I & II \\
\hline Ketersediaan & $\mathrm{m}^{3} /$ detik & 0,64 & 0,50 & 0,41 & 0,33 & 0,67 & 2,16 & 3,07 & 4,76 \\
\hline Kebutuhan & $\mathrm{m}^{3} /$ detik & 0,56 & 0,49 & 0,44 & 7,34 & 7,30 & 3,50 & 2,95 & 3,20 \\
\hline Saldo & $\mathrm{m}^{3} /$ detik & 0,08 & 0,01 & $-0,02$ & $-7,01$ & $-6,63$ & $-1,35$ & 0,11 & 1,56 \\
\hline
\end{tabular}

Tabel 5 menunjukkan saldo air yang terjadi tiap 15 hari pada DAS Tirtomoyo.

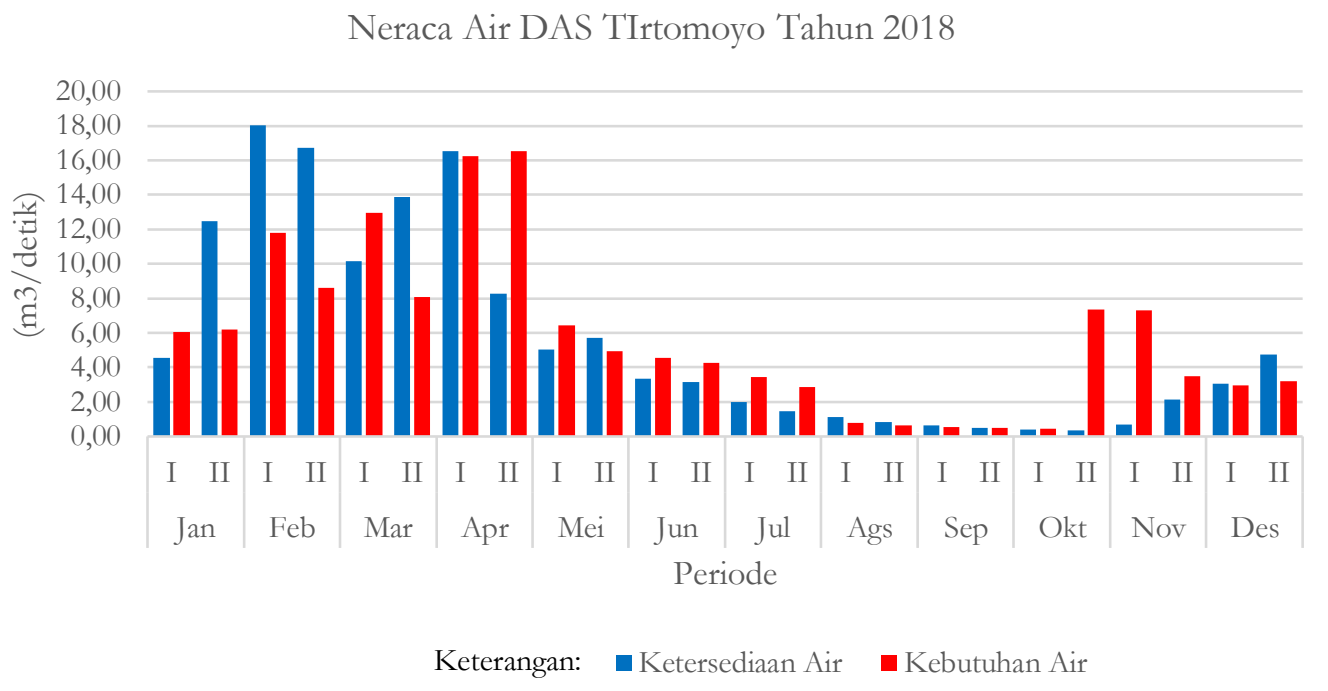

Gambar 3 Neraca air DAS Tirtomoyo

Gambar 3 menunjukkan neraca air yang terjadi tiap 15 hari pada DAS Tirtomoyo.

\section{KESIMPULAN}

Berdasarkan pada analisis dan pembahasan dapat di ambil kesimpulan sebagai berikut:

1. Berdasarkan hasil perhitungan didapatkan nilai ketersediaan air terbesar pada bulan Februari periode 15 harian pertama sebesar 18,0421 m3/detik dan ketersediaan air terkecil pada bulan Oktober periode 15 harian pertama sebesar $0,4149 \mathrm{~m} 3 /$ detik.

Berdasarkan hasil perhitungan didapatkan nilai kebutuhan air terbesar pada bulan April periode 15 harian kedua sebesar 16,5492 m3/detik dan ketersediaan air terkecil pada bulan Oktober periode 15 harian pertama 0,4352 $\mathrm{m} 3 /$ detik.

2. Prediksi hujan tahun 2018 diperoleh menggunakan software Minitab 17 untuk memprediksi ketersediaan air yang terjadi, sedangkan kebutuhan air diprediksi dengan memperkirakan pertambahan penduduk yang terjadi pada 
tahun 2018. Hasil perhitungan menunjukkan bahwa pada tahun 2018 defisit terbesar terjadi pada bulan April periode 15 harian ke dua sebesar - 8,2848 $\mathrm{m}^{3} /$ detik dan surplus terbesar terjadi pada bulan Februari periode 15 harian ke dua sebesar 8,1220 $\mathrm{m}^{3} /$ detik. Neraca air yang terjadi juga menunjukkan pada bulan April hingga November kebutuhan air tidak tercukupi hal ini dapat dilihat dari saldo air yang bernilai negatif sehingga perlu adanya pengelolaan air agar dapat meminimalisir dampak negatif dari hal tersebut.

3. Saldo air 15 harian pada tahun 2018 ditunjukkan pada Gambar 4 berikut:

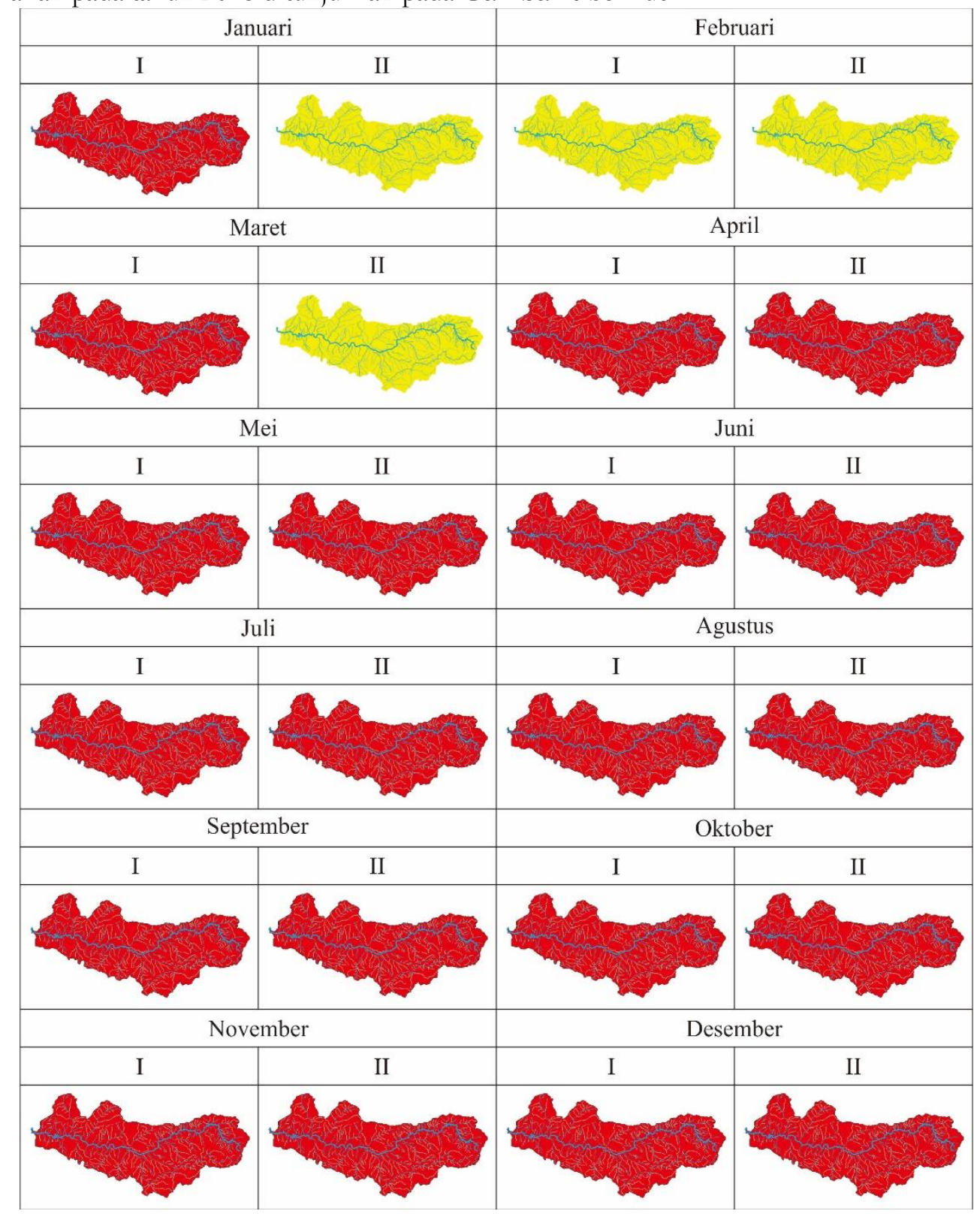

Gambar 4. Prediksi neraca air DAS Tirtomoyo tahun 2018

Gambar 4 adalah prediksi neraca air yang terjadi, warna merah menunjukkan kurang dari 3,2150 $\mathrm{m}^{3} / \mathrm{detik}_{\mathrm{dan}}$ kuning menunjukkan nilai antara 3,2150 $\mathrm{m}^{3} /$ detik - 16,0751 m3/detik.

\section{REKOMENDASI}

1. Pada penelitian ini ketersediaan air hanya dihitung dari air hujan,untuk penelitian selanjutnya , disarankan menambahkan data penggunaan air tanah agar sesuai dengan kebiasaan sehari-hari.

2. Pada penelitian ini data statistik berasal dari BPS, pada penelitian selanjutnya disarankan adanya survei lokasi penelitian, seperti tempat-tempat industri dan peternakan yang ada di lokasi penelitian.

3. Pada penelitian ini sebagai masukan untuk pemerintah atau pembuat kebijakan dalam pengelolaan waduk adalah dengan mengetahui masa kering dan basah yang ditunjukkan dalam neraca air. 


\section{REFERENSI}

Badan Standardisasi Nasiona. Penyusunan Neraca Spacial Sumber Daya Alam - Bagian 1: Sumber Daya Air .2015. Jakarta. Badan Standardisasi Nasional.

Irfani, Alfrida \& Suyanto. 2012. Analisis Neraca Air Sungai Tirtomoyo Sub DAS Bengawan Solo Hulu3. Surakarta. Universitas Sebelas Maret.

Saksono, Lukman Hakim Nugroho., Rintis Hadiani \& Setiono. 2013. Prediksi Neraca Air Dengan Metode Perencanaan Bulan Dasar di Daerah Aliran Sungai Tirtomoyo di Kabupaten Wonogiri. Surakarta. Universitas Sebelas Maret.

Setyosari, Yosephina Puspa., Rintis Hadiani \& Suyanto. 2015. Simulasi Hujan Debit Di Daerah Aliran Sungai Bah Bolon Dengan Metode Mock, NRECA dan GR2M. Surakarta. Universitas Sebelas Maret.

Trisasongko, Bambang H., dkk. 2008. Kajian Spasial Kesetimbangan Air pada Skala DAS (Studi Kasus DAS Bengawan Solo Hulu). Kementrian Negara Lingkungan Hidup Republik Indonesia.

Wibowo, Cahyo Adi \& Rintis Hadiani. 2012. Analisi Neraca Air Faerah Aliran Sungai Bengawan Solo Hulu Sub DAS Bengawan Solo Hulu 3. Surakarta. Universitas Sebelas Maret. 